\title{
Sustaining intangible heritage through video game storytelling - the case of the Sami Game Jam
}

\author{
Outi Laitia ${ }^{a *}$ Sabine Harrer ${ }^{\mathrm{b}}$, Satu Uusiautti ${ }^{\mathrm{a}}$, Annakaisa Kultima ${ }^{\mathrm{c}}$ \\ ${ }^{a}$ University of Lapland, Rovaniemi, Finland; ${ }^{b}$ Tampere University, Finland; ${ }^{c}$ Aalto \\ University, Finland
}

All corresponding concerning this article should be addressed to Outi Laiti, University of Lapland, P.O. Box 122, 96101 Rovaniemi, Finland. E-mail: outi.laiti@gmail.com

Outi Laiti is an indigenous PhD researcher at the University of Lapland. Her field of research is digital games, indigenous education and computer science, and focus is on Sámi language and culture in computer game software.

Sabine Harrer is a postdoctoral researcher at the Centre of Excellence in Game Culture Studies, University of Tampere. Their research focuses on cultural videogames criticism, HCI and intersectionality and creation-based knowledge making. She is the author of Games and Bereavement (transcript 2018).

Satu Uusiautti is professor of education, especially educational psychology at the University of Lapland. Her research interests have focused on educational psychology and positive development and human well-being in various contexts, including indigenous cultures. She has also actively participated in development of Sámi education and pedagogy.

Annakaisa Kultima is a postdoctoral researcher at Aalto University School of Arts, Design and Architecture. Her research has been concentrating on the creative processes of game developers and covered various game design trends as well as game jam cultures. 


\title{
Sustaining intangible heritage through video game storytelling - the case of the Sami Game Jam
}

\author{
This article explores how game jams, a rapid collaborative game production \\ format, can work to support the revitalisation of indigenous self-narratives in the \\ context of Sámi culture. The study focuses on the Sami Game Jam, an event \\ designed and carried out in the Northern Finish Sámi community in Utsjoki, in \\ February 2018. Using an ethnographic method including participatory \\ observation, video interviews with Sámi participants, and textual video game \\ analysis, the study first discusses the event design, and how the creation of Sámi \\ themes and priorities created constraints for game design. The variety of themes \\ selected for the jam reflects the diversity of concerns present in contemporary \\ Sámi society, and the need to reflect them in media. Secondly, we address the \\ process of collaborative game development to explore current Sámi experience in \\ a dialogic, open-ended way. Finally, we discuss the games created during the \\ game jam, and how their design translate Sámi themes into playable artefacts. \\ Based on the findings, we conclude how game jamming as a cultural practice can \\ be appropriated for the purpose of sustaining intangible cultural heritage.
}

Keywords: Sámi; indigenous studies; intangible heritage; game jam; videogames; revitalisation

\section{Introduction}

In this article, we explore in what ways the new digital collaboration format of game jams can serve as a tool for Sámi indigenous revitalisation. Game jams are short social game creation events during which small development teams prototype digital or analogue games from scratch, usually by responding to a given design constraint (Kultima 2015). Previous research on game jams has documented the community aspects of such jam settings (Kultima 2018), including its potential for collective learning (Fowler et al. 2013), and interpersonal validation (Harrer 2019). The reasons for choosing game jamming as a heritage tool are thus twofold. First, game jamming as 
a format for digital collaboration has gained immense popularity since 2002 (Kultima 2015). Its focus on bringing game developers together to improve their technical skills gives it an appeal of innovativeness and future orientation. In the context of Sámi heritage, game jamming seems an appropriate tool to counteract old stigmas around indigenous cultures as "of the past". Game jamming juxtaposes Sámi heritage with contemporary digital tools, emphasising the survival of Sámi values and traditions. Secondly, game jams have been successfully utilised to address a number of sensitive cultural issues, including gender and sexual diversity (Lyst Jam, Boob Jam), historical trauma (Fukushima Game Jam), and news ethics (Fake News Jam). Identifying Sámi heritage as a theme for game jamming thus both continues an established tradition of political game making, and includes Sámi issues on the agenda of digital futures. What is at stake, then, is the question of how game jam settings can be used in indigenous contexts to address ongoing struggles and to strengthen indigenous community selfnarratives.

\section{The tangible and intangible heritage of the Sámi culture}

Intangible heritage as expressed in Sámi culture is an ongoing productive journey for expressions of authentic 21st century identities. These identities are necessarily fluid and elude stereotypes of traditional versus digital. In Finland today, the Constitution of Finland recognises the Sámi as an indigenous people (Ministry of Justice 1999), meaning that they can develop their language and culture. This includes expressions of Sámi indigenous knowledge, traditional livelihoods and all other ways in which Sámi people choose to articulate their culture (Ministry of Education and Culture 2018; Näkkäläjärvi 2016; Sámediggi 2019). 
This means that any everyday life practice, performed by a member of the Sámi community, can be considered an element of intangible cultural heritage, whether this practice reflects traditional Sámi ways or not (see also Berg-Nordlie 2011). That said, the line between tangible and intangible heritage is blurred (Ministry of Education and Culture 2018). The mixing and mashing of traditional and contemporary elements make a frequent choice for many Sámi. However, the introduction of new media into Sámi lives conjures up questions around agency and cultural appropriation. On whose terms are new technologies applied to Sámi contexts? If used by Sámi community members, new technologies can enhance old traditions. If change is imposed from the outside, assimilation is enforced (Aikio 2010). Most computer systems and software technologies are still designed by and for non-indigenous people, imposing a language, logic and design catering to white western users (Tedre, Kommers, and Sutinen 2002; Laiti 2016).

New technology and game “empires” (Dyer-Witheford and dePeuter 2009) come with the risk of repeating dynamics of assimilation, to which Sámi communities have been subjected over centuries, resulting in the diminishing of natural learning environments, traditional livelihoods and Sámi speakers (Näkkäläjärvi 2016). Assimilation policies have affected indigenous people in general, and Sámi people in particular (Elenius 2006; Lundmark 2008), leaving deep scars in the shape of symbolic vilification of Sámi symbolism (see e.g. Borvo 2001), Sámi educational principles, habits, and language (Kuokkanen 2009).

The endangered situation of Sámi languages and culture makes it crucial to understand intangible heritage and new ways of revitalisation (Olthuis, Kivelä, and Skutnabb-Kangas 2013). Most Sámi people today are part of the mainstream workforce, producing tensions between traditional, formerly devalued lifestyles, and the laws of 
late modern market dynamics. When it comes to approaches of revitalisation, this complex position of present-day Sámi identity must be acknowledged, thinking modernday needs in conjunction with old pedagogic Sámi principles of a holistic, constructivist, collaborative and practice-based lifestyles (Hirvonen 2003; Keskitalo, Uusiautti, and Määttä 2012).

\section{Games and culture revitalization}

One reason to study games as a potential tool for Sámi heritage revitalisation is the important function games have held in Sámi culture over time (Itkonen 1941, 1948). Sámi games reflected priorities and expressions in relating to the land, as seen in the prominence of animal and nature themes (Itkonen 1941, 1948). When used as a pedagogic tool, games allowed children to imitate working adults via playful practices, enacting roleplay around Sámi traditional livelihoods. Hence, Sámi play and games have also been a platform to pass on traditional knowledge.

According to Itkonen (1941, 1948), Sámi people have also designed many original games. One of these traditional games is a wooden board game, Sáhkku. Sáhkku is a game of the Tâb game family and included pieces with carvings containing elements of Sámi mythology. Christian colonizers regarded these elements as potentially dangerous, who thus fiercely opposed and renamed them "the devil's game". This might have contributed to its erasure after the 1950s (Borvo 2001).

Overall, games have been significant in sustaining livelihood, traditional Sámi pedagogy, as much as in politics of Sámi erasure and colonisation (DuBois 2003). Another reason to explore Sámi indigenous heritage in a digital game making context is that the employment of digital technology in indigenous settings is nothing new. Global efforts around indigenous technology include Aboriginal digital databases (e.g. Verran 
et al. 2007; Christie and Verran 2013), and Virtual Reality art projects (Leavy 2007). More specifically regarding game development, there are increasing efforts to integrate game development tools and indigenous storytelling (e.g. LaPensée 2017)

There also are examples for intersections between indigenous game creation and the gaming market. Perhaps most famously, Never Alone (Kisima Injitchuya) is a game involving the Cook Inlet Tribal Council (2017) featuring the Iñupiaq language through Alaskan Native storytellers' voices. In an attempt to present traditional indigenous storytelling in a contemporary medium, Never Alone's storyline is based on the Kunuuksaayuka story, a piece of intangible heritage. Never Alone’s creative process begs the question of indigenous agency. While inspired by Cook Inlet Tribal Council ideas, the development team had only one indigenous member. Furthermore, as a commercial game, Never Alone was partly driven by the need to generate revenues, compromising ways to represent indigenous heritage. This questions how much of the game was an attempt to appeal to Western player audiences, rendering well-meaning attempts at indigenous representation mere ornamentation. Overall, this may lead to dynamics where the game performs preservation at the cost of repeating colonial structures: Western mechanics decorated by "authentic” indigenous ornamentation. Acutely aware of a reality in which indigenous languages and practices erode, indigenous communities are caught in a situation of ethnostress: There is urgency in preserving cultural elements, but doing so by the rules of an industry may further erase their voices through cultural appropriation and self-censorship. Indigenous game makers may choose to go with harmful conventions out of fear of losing their cultural heritage altogether. Overall, the indigenous pressure for rapid solutions against cultural losses potentially leads to both positive and negative results, dynamics to keep in mind for this study’s context. 


\section{Method}

We use an ethnographic research lens (Hammersley and Atkinson 1983), comprising participatory observation, qualitative interviewing, and textual analysis of the games produced during the 5-day long 2018 Sámi Game Jam in Utsjoki. The production of culture happened in a literal sense, with the ephemeral Sami Game Jam context being formed for the sake of both experimenting with and reflecting on a digital creative process.

The research context included two participant groups identified through their contribution to the game jam. The first group consists of Sámi people whose lived experience and expertise on Sámi techniques shaped creative decision making, e.g. the interpretation of the themes and their appropriate treatment as a playable experience. The second group includes the cohort of international game developers without a Sámi background who joined the event because of their previous experience with game development and game jams as a co-creative method. While we consider how both groups contributed to the game jam, the interview sample (N=7) focuses on Sámi participants and their experience of the event. The intention was to prioritise these voices, given their stakes in the struggle for a wider recognition of Sámi culture, e.g. how revitalisation might affect their lives and opportunities in the future.

\section{Participatory observation}

We chose participatory observations as a primary tool (see DeWalt and DeWalt 2011). Most insights in this article are based on field notes by Outi Laiti attending the event as local co-organiser and Sámi participant. Field notes were taken daily during the game jam, and as part of design considerations leading up to it. Accompanying these notes, Laiti used a structured questionnaire for self-reflection containing five questions:

- How did Sámi culture manifest itself during the day? 
- What kind of learning experiences were reported by the participants?

- What kind of challenges were reported by the participants?

- What noteworthy phenomena emerged during the day?

- What problem-solving activities did the participants engage in?

We designed these questions to prompt self-observation, but also as a tool to centre attention on our ongoing participation in the process of game design. Our active involvement produced affective data based on our subject position as participatory observer. As a Sámi community member and core organiser of the game jam, Laiti’s stakes were different than the ones of Sabine Harrer, an international creator who engaged with Sámi politics for the first time. Considering these differences, interpretations of the ethnographic site varied with each researchers' history and past experience (Creswell and Poth 2018).

\section{Jammer interviews}

In addition to participatory observation, extensive video interviews were conducted with most of the game jammers on the jam's last day. The original purpose of these videos was to serve as audio commentary for a planned exhibition demonstrating the outcome of the Sami Game Jam.

In this article, we use the term jammers when referring to the Sami Game Jam participants and participants when referring the participants in this study. The participants of this research were selected from among the jammers. The participants were 42 experienced game developers from around the world and Sámi people from around Finland. The Sámi participants were not game developers. People were guided to introduce themselves in Discord discussion channel and collaborate weeks before the event. Thirteen jammers identified themselves as Sámi either in the Discord channel 
discussions before the Sami Game Jam, lávvu reflections during the jam or video interviews at the end of it. The age range of Sámi jammers was 13 to 46 and the average age 27.

For this study, a sample of seven interviews with Sámi participants (P1-P7) was selected, comprising 68 minutes and 48 seconds of material. The interviews were in Finnish $(\mathrm{N}=4)$ or Northern Sámi language $(\mathrm{N}=3)$, and later translated and transcribed by Laiti. She was also involved in creating three questions to be asked by the interviewer who also participated as a jammer:

- How does Sámi culture manifest itself in your game and in Sami Game Jam games?

- What did you learn about game development during Sami Game Jam?

- What do you want people to learn when they play your game?

These questions focused on the educational aspects of the jam, including both levels of game development and Sámi culture as well as the developers’ creative intent. Especially the third question invited answers on the expectations game developers and Sámi participants might have regarding the impact of their games, either on Sámi players or others.

When it comes to data interpretation, interview analysis followed the principles of qualitative content analysis (Bengtsson 2016), including decontextualising data to identify meaning units, a comparison with the original data, and a thematic clustering and categorisation of themes. The development of themes was guided by a focus on intangible heritage and Sámi pedagogy principles: How did the data reflect aspects pertaining to aspects like collaboration, learning by practice, or educational storytelling? Interviewee data was treated confidentially and anonymised. 


\section{Videogame analysis}

A textual analysis of the games (Harrer 2018b; Smethurst 2015) made at Sami Game Jam was conducted, considering the importance of material artefacts produced during the event. In conjunction with participatory observation, which reflects on the process of designing and running the game jam, as well as participating in it, and the interviews, which make sense of this process from a Sámi perspective, textual analysis looks at how what has been made can be related back to Sámi intangible heritage.

The games are visceral results both of the organisers' efforts in constraining and facilitating the event, and the participants' participation in game development. This makes them interesting as artefacts to look at, since they speak of the labour process, and priorities in dealing with the provided Sámi themes. In this context, both the games' technical features, their aesthetics, as well as their perception by designers and players becomes a part of Sámi intangible heritage. The games analysis follows three questions:

- How do the games approach their Sámi themes?

- What technologies and aesthetics are used to convey it to the player?

- How does this relate to features of intangible Sámi heritage?

\section{Limitations and ethical considerations}

We have followed the ethical guidelines of Ethical Conduct for Research Involving Humans (Canadian Institutes of Health Research, Natural Sciences and Engineering Research Council of Canada, and Social Sciences and Humanities Research Council of Canada 1998) and the Finnish National Board on Research Integrity (TENK). The research was explained to the participants before it took place and written consent was asked from all interviewees.

Usually, research on Sámi intangible heritage requires a permission from the Sámi Parliament. Since the head researcher Laiti is a member of the Sámi community, 
no permission was asked to conduct this research from the parliament. The cultural heritage belongs to the Sámi community members and the indigenous research methods gives the permission to do necessary research. The games produced in the Sámi Game Jam are in use within the community, as The Sámi Parliament has accepted the games as a part of materials for Sámi education (Oktavuohta 2019). The research participants are being referred with the codes P1-P7 in the results section. Excerpts from the data illustrate their thoughts and perceptions in the interviews.

\section{Results}

\section{Designing the Sami Game Jam}

In what follows, we describe the design of the Sami Game Jam features, focusing on the event venue, jam structure, participants, and the development of themes; an integral part of many game jams (Harrer 2019). The event occurred at the Áilegas cultural centre located in the municipality centre of Utsjoki. Game development proper happened inside the centre, but adjacent to it, a traditional lávvu, a Sámi tent containing a fireplace, served as the site for daily evening reflections. In Sámi culture, the lávvu and its campfire is a communal place for passing on knowledge (Aikio 2010; Hirvonen 2003; Keskitalo et al. 2012, Kultima and Laiti 2019). The importance of lávvu was highlighted also in the Sami Game Jam logo that represented the smoke hole of lávvu seen from the inside (Figure 1). The lávvu’s purpose was to infuse the game development process with Sámi educational values, inviting jammers to share their daily experiences with each other in an intimate setting.

Insert Fig 1 around here

For the schedule, the Sami Game Jam used a version of the game jam formula (Kultima 2015) with three important variations. First, the jam used a traditional 48-hour 
game development model, but embedded it in a cultural programme, including two days in the beginning for acclimatisation and a Sámi cultural day. These two days catered to the group of international jammers whose knowledge of Sámi history and politics were assumed to be low.

Secondly, while game jams are usually low-pressure sites for experimentation and potential creative failure, the contributions made at the Sami Game Jam were intended to be showcased in an art exhibition. This information introduced a sense of urgency and performance pressure unusual for game jams. There were stakes involved in succeeding to deliver interesting games, as failure to do so would affect a whole community rather than just a single team.

Thirdly, in many game jam settings, a recommended single theme serves as a creative prompt to kick off the game development process (Harrer 2019). In the Sami Game Jam, a number of themes were developed to help teams engage with different aspects of Sámi culture.

Coming up with appropriate themes for Sami Game Jam was itself conducted as a jam activity, happening at the game jam organisers' meeting and workshop Jam Jam at Sappee, Finland in 2017. It was decided that the jammers attending Sami Game Jam would work on individual themes covering a broad range of Sámi subjects. The 12 themes addressed several issues, ranging from geographical and climatic factors ("People of the Eight Seasons”, "Ultima Thule”, “Living outside the Samiland”), political struggles (“Border-Crossing People”, "Persistent Stereotypes”, “One Nation, Many Languages”, “Strangers in Their Own Land”, “The Future Sami), to psychosocial experience (“Ethnostress”, “Lost Memories”, “Cross-Generational Stories”). The themes with descriptions can be found at https://samigamejam.com/themes/. 
The theme design’s second phase involved two Sámi researchers evaluating and refining the themes. Overall, the feedback was positive, with minor suggestions for emphasising Sámi resilience and agency. Instead of repeating the tired narrative of Sámi people as colonised, disowned, and oppressed, the idea was to signal ways of survival, living on despite past trauma.

In its final shape, the Sami Game Jam themes consisted of a title, an evocative flavour text, and an explanation clarifying the themes for jammers unfamiliar with the concepts. By blending emotional and factual information, the descriptions were supposed to open engagement with the themes on an affective level before explaining its context and relevance for Sámi life. Some interviewees mentioned this integration between overall relevance and specific life experience, praising the variety which "did quite well cover all the themes when thinking about language and culture” (P3), providing interesting starting points. However, there was also concern about the way jammers would be able to appropriately reflect the themes in their games.

P1: "Well, when I saw those themes, I thought they were really important topics and they were just the kind of things we have to deal with. But I probably also had such feelings that here you have to be very precise about how they are handled. And of course it was good to see that there were invited Sámi experts or local people who know about them and know how to tell them.”

For P1, an appropriate interpretation of the themes hinges on the "invited Sámi experts or local people who know about [the themes]" and would be able to guide their translation into game form. This suggests that the themes would not have been enough to craft meaningful playful artefacts without being rooted in Sámi contextual experience breathing life into them. This brought up another concern among interviewees, namely how confident they felt sharing their life experience with the jam team, and how it would impact the results: 
P4: "Yes I liked those themes. They were just a little bit tricky. I began to think about my own life how they relate to it. And I gave some groups some things about my life. They had a theme that was more involved in my life. I have lived in cities, like a city Sámi. And that was one theme. That's how I got it from my own life and my experiences probably went into that game.”

In this passage, P4 admits the "trickiness" of articulating the relationship between the themes and their life experience. This highlights the pressure of speaking on behalf of a certain experience. While the themes covered several issues, inviting different conversations, the Sámi jammers were still expected to lead these conversations in “correct” ways, also catering to the knowledge level of the international jammers.

\section{The game jamming experience}

Here we analyze the game development process, and how discussing and implementing the themes through cross-cultural collaboration challenged assumptions about Sámi identity, and indigenous identity more broadly. Most importantly, the process of negotiating what Sámi issues actually meant highlighted the positionality and diversity of Sámi creators. This could be observed throughout from the initial stages of brainstorming to design and completion of the final games. These stages were characterised by a close collaboration between Sámi and international jammers, forming six teams.

It had been decided that each team would select two themes, which turned out an appropriate decision, given the fluid interpretations of Sámi experiences. Despite deciding to work within a rigid team structure for the sake of ensuring a professional and rapid game development process, which would elicit presentable results, some Sámi participants offered to participate in various groups, based on interest and expertise. This created an environment of open communication, with conversations flowing among and between groups, breaking up borders between teams for the sake of a 
collective experience in which each game could arrive at its best form by being allowed to receive advice from different sides.

From the beginning, the range of themes in conjunction with the Sámi jammers’ responses to them suggested the Sámi identity project as fragmented, contested, and work-in-progress. This was particularly tangible in teams featuring multiple Sámi jammers, such as the team Sabine Harrer joined. This team had initially selected “Ethnostress”, eliciting radically different responses from the two Sámi jammers. While one team member felt deeply connected to this theme and how much it affected their life, the other team member heavily rejected its implication as irrelevant and, indeed, harmful towards the more traditional lifestyle they had chosen for themselves. Instead, they expressed a passionate interest for creating a salmon fishing game, a topic which, again, did not seem to resonate with the first team member. Eventually, the rest of the team prioritised one of the themes with the consequence of one of the Sámi members dropping out of the jam.

This illustrates that the motives of Sámi participants to join the jam in the first place differed widely and displayed a diversity of assumptions and wishes. For the rest of Harrer's team, the initial conflict was an appropriate lesson on the fluidity of Sámi identity, providing a chance to break with potential assumptions about cultural authenticity before creative work had even started. The case clarified from the beginning that instead of authenticity, complete stories, consistent images, and answers “solving” Sáminess, we would find fragmented experiences, conflicting priorities, and open-ended questions.

Brainstorming eventually led towards a game concept based on two constraints; the game had to respond to the themes, and it had to be playable as part of the prospective Sámi game exhibition. A central focus was on sensitive communication and 
attention to group consensus, which was defined as respectful in several interviews. P3, for instance, noticed the group's cohesion as an important part of their positive experience:

P3: "It was interesting how well our group worked together and sometimes felt that another person already read my thoughts about how I thought the game was going and how to get that culture into it. And we had a really good, good cooperation.” Instead of stereotyping Sámi identity from the outside, the focus was on acknowledging ideas around "Sáminess" as a number of unanswered questions rather than one fixed answer. On an experiential level, the principles of digital game development and Sámi identity formation turned out to be closely related: Both commit to a work in process model of experience, led by personal priorities, mastered through (life)skills, and shared with an affective community of like-minded people playing along.

During the event, the participants started challenging essentialist assumptions about the mutually exclusive nature of Sámi culture and videogames themselves. P1, who had been queried by a concerned reporter, for example reported this:

P1: “[The jam] was an interesting way to combine new customs and the so-called contemporary culture, such as game culture. [...] One reporter came to ask, for example, whether Sámi and game culture fit together. Or whether this somehow ruins the Sámi culture. I replied that no, of course, it is really great to see how they can be matched.”

The reporter's question demonstrates the common, problematic investment in the idea that indigenous culture should be confined to their mythological place in the past where it will stay pure and unaffected by the "ruining” impacts of contemporary media culture. But P1 refuses to accept this division between games culture and their cultural heritage. According to them, "it feels that some are trying to control what the Sámi can do based on their own imagination” (P1).

An integral part of game jams is the time constraint. While traditional jammers are somewhat accustomed to this kind of creative pressure, some voiced initial doubt in 
the interviews. P4, for instance, was "wondering that when we have three to four days, how can it be possible to get anything done that we can show to people.” On the other hand, the short time period seemed like an important source for feelings of success and euphoria:

P3: "Well, I would say that in such a short period of time we succeeded very well and I was amazed that such things can be produced in such a short time. I was really satisfied with the results.”

This connected to the tangible success of completing something as part of a team with reputable technical skills commonly associated with the "futuristic" medium of videogames. This breaks with the persistence of game development and digital technology as domains controlled by white western men (Passmore, Byrk and Mandrik 2018). Digital games are, in fact, becoming a Sámi medium communicating Sámi interests through rules, mechanics, sounds, words, and controls.

After the games had been finished, they were presented to the audience. The teams went on stage together, showing a small trailer of their creations, explaining the premise, and then demonstrating, turning the theatre into a pop-up arcade.

\section{Modelling Sámi experience through gameplay}

During Sami Game Jam, six games were developed, three of which we discuss here in detail. It is noteworthy that many of the games revolved around nature themes, making protagonists traverse Arctic landscapes (Rievssat, Mu Luodda, Jođus, Lost Memories), sometimes in the role of animals (Sáivu, Rievssat). Furthermore, several teams decided to experiment with novel input devices, including Virtual Reality (VR - Lost Memories), Leap Motion (Rievssat), and custom-made controllers (Jođus, Rievssat) Rievssat

In Rievssat the player steps in the role of the Northern Finnish ptarmigan bird, flying through a changing landscape by moving their hand across the Leap Motion controls. 
Additionally, a custom-built pedal is used to gain speed and altitude, helping the bird navigate air currents. The game was built around the two themes "Strangers in Their Own Land” and “The People of Eight Seasons”, conveyed through the journey of the bird traversing different landscapes while becoming more and more alienated from a world. The bird's habitat, originally expansive and accessible, is increasingly threatened by a growing amount of roads, traps and other infrastructure, forcing the bird to take detours to procure food.

The bird's struggles stand for the feeling of alienation from a land which is supposed to provide safety and nourishment, but becomes increasingly subjected by colonising forces, becoming increasingly uninhabitable. Furthermore, the game presents a narrative in which a balanced system between nature and its inhabitants is disturbed, leading to conflict:

P7: "In our game... there is a lot of description of how the arrival of new people has influenced to the environment of the ptarmigan, even though it was the first to be here. The game has eight levels, each dedicated to a season. The player's task is to survive each season by finding food, which gets more difficult proportionally to the amount of human traces in nature.”

Overall, Rievssat can be regarded as a game continuing the rich Sámi tradition of animal roleplay (Itkonen 1941, 1948). The imitation of the bird happens through hand gestures, asking the player to become the bird by performing a subtle dance. This creates a situation in which the player smoothly transitions between the roles of performer-player exploring eight seasons (Figure 2), while learning about subtle dynamics of estrangement experienced by many Sámi people.

Insert Fig 2 around here

\section{Lost memories}

Lost Memories was created based on the themes of "Living outside Samiland" and the titular “Lost Memories”. The game uses VR, taking players into a 3D representation of 
two different worlds. The first world is an urban city apartment, complete with pizza, jazz music, and modern furniture. This world is connected to a different world via a magical portal. Through the portal, the player finds themselves in a contemplative Sámiland outdoors environment featuring a roaring campfire, heavy snow, northern lights and pieces of traditional handicraft, duodji. For some time, the player can move back and forth between these worlds, using the ever-shrinking portal. This raises the question whether the portal will disappear over time (it will), and whether this means that the player has to choose one of the two worlds.

By staging a conflict between two equally desirable locations, Lost Memories makes tangible the impossible task of choosing a “correct” Sámi lifestyle. It is obvious that both scenarios - the Arctic outdoors (Figure 3), and the urban indoors (Figure 4), are potential places to live a Sámi life in. However, the game imposes the request to make a "forever choice”, simulating the pressure on Sámi community members to determine their lives as either traditional or progressive.

The portal's closing might itself stand for the level of patience expressed by a community whose survival is dependent on clear-cut alliances. It cannot afford to wait forever, but demands clarity over an individual's choice. The stress the player experiences when oscillating between the worlds, perhaps hastily throwing a pizza slice through the portal, or playing with the fire, can also stand for the "Ethnostress" of representing Sámi heritage correctly. The urgency of the timer increases the felt gravity of the situation. One wrong move and the player will be locked down forever in what now feels like one half of the world ideal.

Insert Fig 3 and Fig 4 around here 
Jođus - On the Move

Jođus interprets the themes of "Border Crossing People" and "The Future Sami”. The player stands on a balancing board using wood and felt provided by the Utsjoki Sámi school. Similarly to Lost Memories, the landscape is divided in two: One part of the screen displays an urban environment, featuring architecture, city infrastructure in grey tones. The other part contains nature elements such as trees, rocks, and a river.

In displaying contrasts between the city and the country, one important design choice had been to break with expectations: “Traditional” country Sámi lifestyles might involve the use of high-tech devices, such as helicopters for reindeer herding, or snowmobiles for travel. Moreover, in remote places, one might occasionally yearn for a cup of artisan coffee, or a sushi dinner (Figure 5). Conversely, a city Sámi might be attached to traditional Sámi items such as knives and cups, and might crave a slice of dried reindeer meat.

The design choice to blend city and country elements was perceived as an appropriate way to challenge persistent assumptions about Sámi life. As P3 remarks:

P3: "the game breaks stereotypes, like there is nothing to do when you live in the North or there is no internet connection or that the city would be completely out of Sámi culture because this is all false.”

On the haptic level, the game represents a player's individual journey through the city and the country as a whole-body metaphor. In order to pick up experiences on the way to a future unfolding in front of the character's eyes, one has to literally lean towards a direction one finds exciting. Balancing one's options can be motivated by the pure fun of moving back and forth, or by steering towards an attractive goal. Since the character walks automatically, there is a timing challenge as well, similar to the closing portal in Lost Memories. Most importantly, what will appear on the horizon is not known in the beginning, but all are equally valid choices. 
This validity of different life choices is communicated in the end screen, where the player can review the collected items, each of which contains a conversation piece shared by Sámi jammers during the game jam. For instance, when picking up the Sushi item, one gets a quote on the advantages of city Sámi life: "I like living a lazy life, going to the movies, fancy restaurants, and hanging out in coffee shops. That's easier in the city”.

However, not all quotes are thematically matched to the items, leaving space for more metaphorical interpretations. For instance, the reindeer meat "speaks" to the theme of "Ethnostress", eliciting the following in-game quote: "It's hard to leave when everyone thinks that you are abandoning your people, your culture”. The idea was to make room for potential problematic associations with traditional objects, leaving it up to the player whether they want to think of the game character's journey as a joyful challenge or an amassment of emotional baggage.

Insert Fig 5 around here

\section{Discussion}

\section{Game design, Sámi heritage and intercultural validation}

Games are not the only context where the conflict between the Sámi and mainstreaming culture may appear. However, the ways video games can be developed and, more importantly, used for the purposes of enhancing cultural heritage is relevant to our research. Our purpose was not to compare video games with other media or nonmediated cultural aspects but to focus on analysing the applicability of game jamming from this perspective. As this is somewhat a unique way of approaching the concept of cultural heritage, our intention has been to evaluate the benefits this type of revitalization method can present. Next, we look at the specific issues and points discovered during the process. 
Negotiating the 12 Sámi themes was an important way to guide the direction of the jam and impose constraints in keeping with current community interests. By drawing on the themes' affective and political dimensions, the descriptions provided evocative starting points for the design process. The themes were useful in directing and “accelerating” the design process (cf. Kultima, Alha and Nummenmaa 2016).

The collaborative struggle to express versions of this culture in videogame form was welcomed as an opportunity to update notions of Sáminess, shifting assumptions about Sámi culture as "museum culture” (P1) towards a more accurate contemporary perception. This means that Sami Game Jam was an exercise in working with new tools to honour old knowledge, at the same time validating the capacity of jammers to be both Sámi and skilled game developers. This double identity reverberates earlier discussions on Sámi identity as non-monolithic and consisting of multiple voices (Hafstein 2005). In the context of Sami Game Jam, this multiplicity of voices happened through crosscultural collaboration, stimulating exchange between local, national, and international communities (Hafstein 2005). Rather than common stereotypes, the games represent Sámi culture as a set of dynamic, inherently uncertain life choices.

Furthermore, there was a continuation of ancient Sámi game elements, using nature and animal motifs (Rievssat, Lost Memories, Jođus). Most of the games, including the three examples discussed, used input devices engaging the whole human body in play to experience their game characters and thus engage with concerns of a contemporary Sámi community using high-end gaming hardware. Overall, these elements of the game jam resonate with educational principles of Sámi intangible heritage, focusing on embodied, holistic ways of learning. Rather than framing Sámi intangible heritage as incompatible with digital expressions, maintaining tired dichotomies of old versus new, traditional versus modern, or analogue versus digital, 
Sámi Game Jam created a “digital campfire” (Laiti and Frangou 2019), connecting the jammers around living expressions of Sáminess. This suggests that digital games can be a potent tool for cultural revitalisation, as they allow jammers to express current concerns from the inside, as dynamic rules, mechanics, control schemes, and audiovisual elements.

Noticeably, game jamming is a contemporary cultural technique suitable for different age groups. For young Sámi audiences, the games present an engaging platform to explore familiar stories and environments through immersive gadgets and state-of-the-art technology. On a symbolic level, this presents their culture as something "cool” and contemporary; something one wants to experience with friends, to celebrate, enjoy, and invest in, rather than something to be ashamed of, as was previously the case (Tsalach 2013; Wane 2009; Wilson and Kamana 2009).

Despite this important function of the games for Sámi youngsters, the games might have benefits for adults as well. One should consider that the jammers young adults and worked with highly political themes, rendering game design a mature practice potentially catering as much to adults as children. Indeed, the maturity of ingame struggles might stimulate adult Sámi players’ reflections about their own culture and their place in it. Furthermore, the games might inspire a connection between creators and playful adults whose experiences with the game might be a starting point for conversations and mutual validation. This potential function of mutual validation through artistic creation can be extended to digital game creation (Harrer 2018b).

\section{Limitations and outlook}

The dialogue model of game development created a constellation of mixed cultural settings which is one of many ways to potentially revitalise Sámi intangible heritage. However, there are limitations of the dialogue model which we observed when 
designing, facilitating and attending Sami Game Jam. These limitations connect to the fact that centuries of systematic oppression cannot be undone in a single intervention by well-meaning jammers. By default, culturally mixed settings subtly update historical struggles between Sámi and non-Sámi, although the latter group included jammers from across the world. These struggles affected how the Sami Game Jam was designed, perceived, and participated in.

First, the Sámi organisers invested significant emotional labour into ensuring the event was a success. This is typical for game jams with an interventionist goal, since success or failure comes with political consequences (Kennedy 2018). For Sami Game Jam, the stakes of strengthening the economic, social, and emotional survival of modern-day Sámi members are considerable. An important aspect of ensuring success was to appeal to the international jammers; those owning and providing technical professional resources.

Secondly, much work was put into preventing negative or stereotypical treatment of Sámi culture. The themes were presented in a way which was palatable to outsiders. This limited the risk of letting non-Sámi jammers go with their first impressions or preconceived notions of indigenousness, while keeping them interested and entertained. Overall, the premise of the jam adapted to the worldview of international jammers, framing present-day Sámi discourse in a way that would not alienate them.

Thirdly, the jammers were celebrated in their role as game experts, not in their potential other role as members of a majority society historically amassing privilege and wealth on the backs of indigenous people. While some of the jammers were not from privileged countries, all of them came with skills associated with the "global North"; programming, agile development, and design. This meant that there was a focus on the 
positive aspects of the dialogue, rather than a critical investigation of neocolonial dynamics and game creators’ roles in it (Harrer 2018a). Despite the fact that digital game expertise is part of an empire (Dyer-Witheford and de Peuter 2009) in part built on exploiting of minority cultures (Huntemann 2013), addressing this problem at Sámi Game Jam might have alienated some international game developers and it was therefore avoided.

Overall, this raises the question to what extent the investment in the comfort of non-Sámi jammers expended resources which could have been invested elsewhere (see also Murray 1997). After all, despite their well-meaning participation in the jam, nonSami participants went back to continue their lives elsewhere, their portfolios now enriched by a prestigious project. From an organisational point of view, the inclusion of non-Sámi participants was a crucial strategy to allow knowledge transfer of tools beneficial to future Sámi game developers.

In that sense, the collaboration between Sámi and non-Sámi jammers was embraced as a first step on a long road of self-owned revitalisation through Sámiexclusive game development. The idea is not to pressure Sámi jammers into culturally exclusive game production spaces, but to allow for indigenous digital skills to thrive without the expectation to accommodate non-Sámi people. One important purpose of the Sami Game Jam was to make space for Sámi participants to acquire technical expertise with game making tools in a collaborative atmosphere. As for potential future work, one trajectory of revitalisation game jams might be a game jam exclusive to Sámi and other indigenous communities. Partnering with other indigenous communities may further highlight commonalities and differences, both concerning approaches to game development, tactics of survival, as well as politics of revitalisation itself (LaPensée 2017). 


\section{Acknowledgements}

The Sami Game Jam event received a grant from the Majaoja foundation and it was also funded by the municipality of Utsjoki, Finnish Game Jam organization, Neogames, Ludocraft, Veikkaus and Fingersoft. We would like to thank the Academy of Finland funded Centre of Excellence in Game Culture Studies, Tampere University as well as Aalto University for supporting this research.

\section{References}

Aikio, A. 2010. Olmmošhan gal birge - áššit mat ovddidit birgema [Human will get along - things that promote getting along]. Karasjok: Cálliidlágádus.

Bengtsson, M. 2016. "How to Plan and Perform a Qualitative Study Using Content Analysis.” NursingPlus Open 2: 8-14. doi: 10.1016/j.npls.2016.01.001

Berg-Nordlie, M. 2011. "Need and Misery in the Eastern Periphery: Nordic Sámi Media Debate on the Kola Sámi.” Acta Borealia 28: 19-36. doi: 10.1080/08003831.2011.575657

Borvo, A. 2001. "Sáhkku, The "Devil's Game.” Board Games Studies 4: 33-52.

Canadian Institutes of Health Research, Natural Sciences and Engineering Research Council of Canada, and Social Sciences and Humanities Research Council of Canada. 1998. Tri-Council Policy Statement: Ethical Conduct for Research Involving Humans. https://bit.ly/2xxNjqk.

Christie, M., and H. Verran. 2013. "Digital Lives in Postcolonial Aboriginal Australia", Journal of Material Culture 18 (3): 299-317. doi: 10.1177/1359183513492081

Cook Inlet Tribal Council. 2017. "Storytelling for the Next Generation: How a NonProfit in Alaska Harnessed the Power of Video Games to Share and Celebrate Cultures.” In The Interactive Past. Archaeology, Heritage, \& Video Games, edited by A.A.A. Mol, C.E. Ariese-Vandemeulebroucke, K.H.J. Boom, and A. Politopoulos, 21-32. Leiden: Sidestone Press.

Creswell, J.W., and C.N. Poth. 2018. Qualitative Inquiry \& Research Design. Choosing among Five Approaches. 4 ed. London: Sage.

DeWalt, K.M., and B.R. DeWalt. 2011. Participant Observation. A Guide for Fieldworkers. Plymouth: AltaMira Press. 
DuBois, T.A. 2003. “Fragments of Lappish Mythology.” Scandinavian Studies 75 (4):615-618.

Dyer-Witheford, N and G. de Peuter. 2009. Games of Empire. Minneapolis, MN: University of Minnesota Press.

Elenius, L. 2006. Nationalstat och minoritetspolitik: Samer och finskspråkiga minoriteter i ett jämförande nordiskt perspektiv [The National State and Minority Politics: The Sámi and Finnish-speaking Minorities from a Comparative Nordic Perspective]. Lund: Studentlitteratur.

Fowler, A., J. Pirker, I. Pollok, B. Campagnola de Paula, M. Echeveste, and M. Gómez. 2013. Understanding the benefits of game jams. Conference presentation in ITiCSE '13, Arequipa, Peru.

Hafstein, V. T. 2005. “The Making of Intangible Cultural Heritage: Tradition and Authenticity, Community and Humanity.” PhD dissertation, University of California, CA, USA.

Hammersley, M., and P. Atkinson. 1983. Ethnography. Principles in Practice. London: Tavistock Publications.

Harrer, S. 2018a. “Casual Empire: Video Games as Neocolonial Praxis”. Open Library of Humanities 4 (1): 1-28. doi: 10.16995/olh.210

Harrer, S. 2018b. Games and Bereavement: How Videogames Represent Attachment, Loss, and Grief. Bielefeld: transcript.

Harrer, S. 2019. “Radical Jamming: Sketching Radical Design Principles for Game Creation Workshops”, Proceedings of the International Conference on Game Jams, Hackathons and Game Creation Events 2019. doi: 10.1145/3316287.3316297

Hirvonen, V. 2003. Mo sámáidahttit skuvlla?: Sámi oahpaheaddjiid oainnut ja sámi skuvlla ollašuhttin : reforpma 97 evalueren [Sámi culture and the school: Reflections by the Sámi teachers and the realization of the Sámi school: An evaluation study of reform 97]. Kárášjohka: ČalliidLágádus.

Huntemann, N. 2013. "Women in Video Games: The Case of Hardware Production and Promotion.” In Gaming Globally, edited by N. Huntemann and B. Aslinger, 4157. New York: Palgrave Macmillan. doi: 10.1057/9781137006332_3

Itkonen, T.I. 1941. Lappalaisten leikit ja ajanvietot [Lappish Games and Activities]. Helsinki: Lapin sivistysseura.

Itkonen, T.I. 1948. Suomen lappalaiset [Sámi People in Finland]. Helsinki: WSOY. 
Keskitalo, P., S. Uusiautti, and K. Määttä. 2012. "How to Make the Small Indigenous Cultures Bloom? Special Traits of Sámi Education in Finland.” Current Issues in Comparative Education 15 (1):52-63.

Kennedy, H.W. 2018. "Game Jam As Feminist Methodology: The Affective Labors of Intervention in the Ludic Economy.” Games and Culture 13 (7), 708-727. doi: $10.1177 / 1555412018764992$

Kultima, A. 2015. “Defining Game Jam.” Proceedings of the 10th International Conference on the Foundations of Digital Games (FDG 2015), Pacific Grove, CA, USA.

Kultima, A. 2018. “Game Design Praxiology.” PhD diss., University of Tampere, Finland.

Kultima, A., K. Alha, and T. Nummenmaa. 2016. ”Design Constraints in Game Design. Case: Survival Mode Game Jam 2016.” GJH\&GC '16 Proceedings of the International Conference on Game Jams, Hackathons, and Game Creation Events, 22-29. New York, NY: ACM. doi: 10.1145/2897167.2897174.

Kultima, A., and O. Laiti. 2019. "Sami Game Jam - Learning, Exploring, Reflecting and Sharing Indigenous Culture through Game Jamming.” Proceedings of the 2019 DiGRA International Conference: Game, Play and the Emerging LudoMix. http://www.digra.org/digital-library/publications/sami-game-jam-learningexploring-reflecting-and-sharing-indigenous-culture-through-game-jamming/

Kuokkanen, R. 2009. Boaris dego eana: eamiálbmogiid diehtu, filosofiijat ja dutkan [As Old as the Earth: Indigenous Knowledge, Philosophies and Research]. Karasjok: Cálliidlágádus.

Laiti, O. 2016. "Ethnoprogramming: an Indigenous Approach to Computer Programming: a Case Study in Ohcejohka Area Comprehensive Schools.” Master's thesis, University of Lapland, Finland. http://urn.fi/URN:NBN:fi:ula201612021380

Laiti, O., and S. Frangou. 2019. "Social Aspects of Learning with and through ICTs: Sami People in the Circumpolar North.” International Journal of Multicultural Education 21 (1):5-21. doi: 10.18251/ijme.v21i1.1728

LaPensée, E. 2017. “Self-Determination in Indigenous Games.” In Routledge Companion to Media Studies and Digital Humanities, edited by J. Sayers, 128137. Abingdon: Routledge. 
Leavy, B. 2007. "Digital Songlines : Digitising the Arts, Culture and Heritage Landscape of Aboriginal Australia”. In Information Technology and Indigenous People, edited by L. Dyson, M. Hendriks, and S. Grant, 159-168. Hershey, PA: Idea Group Publishing:

Lundmark, L. 2008. Stulet land: svensk makt på samisk mark [Stolen Land: the Swedish Power in the Sámi Land]. Stockholm: Ordfront Förlag.

Ministry of Education and Culture. 2018. Saamelaisten tarpeet henkisen omaisuuden suojaan tekijänoikeussuojan ja tavaramerkkisuojan näkökulmasta - erityisesti duodji-käsityön ja saamenpuvun osalta [Need of the Sámi People for Intellectual Property Protection, Particularly from the Viewpoint of Copyright and Trademarks- Especially with Regard to Duodji Handicrafts and Sámi Dresses]. Helsinki: Publications of the Ministry of Education and Culture.

Ministry of Justice. 1999. The Constitution of Finland. https://www.finlex.fi/fi/laki/kaannokset/1999/en19990731.pdf

Murray, J. 1997. Hamlet on the Holodeck. The Future of Narrative in Cyberspace. Massachusetts: MIT Press.

Näkkäläjärvi, K. 2016. Saamelaisten aineeton kulttuuriperintö ja sen suojelu [The Intangible Cultural Heritage of the Sámi and Its Protection]. http://www.aineetonkulttuuriperinto.fi/fi/File/3015/nakkalajarvi-inari.pdf.

Oktavuohta. 2019. Saamelaistietoa opetukseen [Sámi Information for Education]. https://www.oktavuohta.com/levyraati

Olthuis, M.-L., S. Kivelä, and T. Skutnabb-Kangas. 2013. Revitalising Indigenous Languages. How to Create a Lost Generation. Bristol: Multilingual Matters.

Passmore, C., M. Birk, and R. Mandryk. 2018. “The Privilege of Immersion: Racial and Ethnic Experiences, Perceptions, and Beliefs in Digital Gaming”. In Proceedings of the 2018 CHI Conference on Human Factors in Computing Systems (CHI '18). ACM, New York, NY, USA, Article 383. doi: $10.1145 / 3173574.3173957$

Sámediggi [Sámi Parliament]. 2019. Culturally Responsible Sámi Tourism. https://www.samediggi.fi/ongoing-projects/culturally-responsible-samitourism/?lang=en

Smethurst, T. 2015. Playing with Trauma in Video Games: Interreactivity, Empathy, Perpetration (unpublished doctoral dissertation). 
Tedre, M., P. Kommers, and E. Sutinen. 2002. Ethnocomputing. A Multicultural View on Computer Science. Proceedings of the IEEE conference ICALT 2002, Kazan: Russia, 195-199.

Tsalach, C. 2013. "Between Silence and Speech. Autoethnography as an Othernessresisting Practice.” Qualitative Inquiry 19 (2):71-80. doi:10.1177/1077800412462986

Verran, H, M. Christie, B. Anbins-King, T. Van Weeren, and W. Yunupingu. 2007. "Designing digital knowledge management tools with Aboriginal Australians.” Digital Creativity 18(3), 129-142. doi:10.1080/14626260701531944

Wane, N.N. 2009. “Indigenous Education and Cultural Resistance: A Decolonizing Project.” Curriculum Inquiry 39 (1):159-178. doi:10.1111/j.1467873X.2008.01443.X

Wilson, W.H., and K. Kamana. 2009. "Indigenous Youth Bilingualism from a Hawaiian Activist Perspective.” Journal of Language, Identity, and Education 8:369-375. doi:10.1080/15348450903305148 


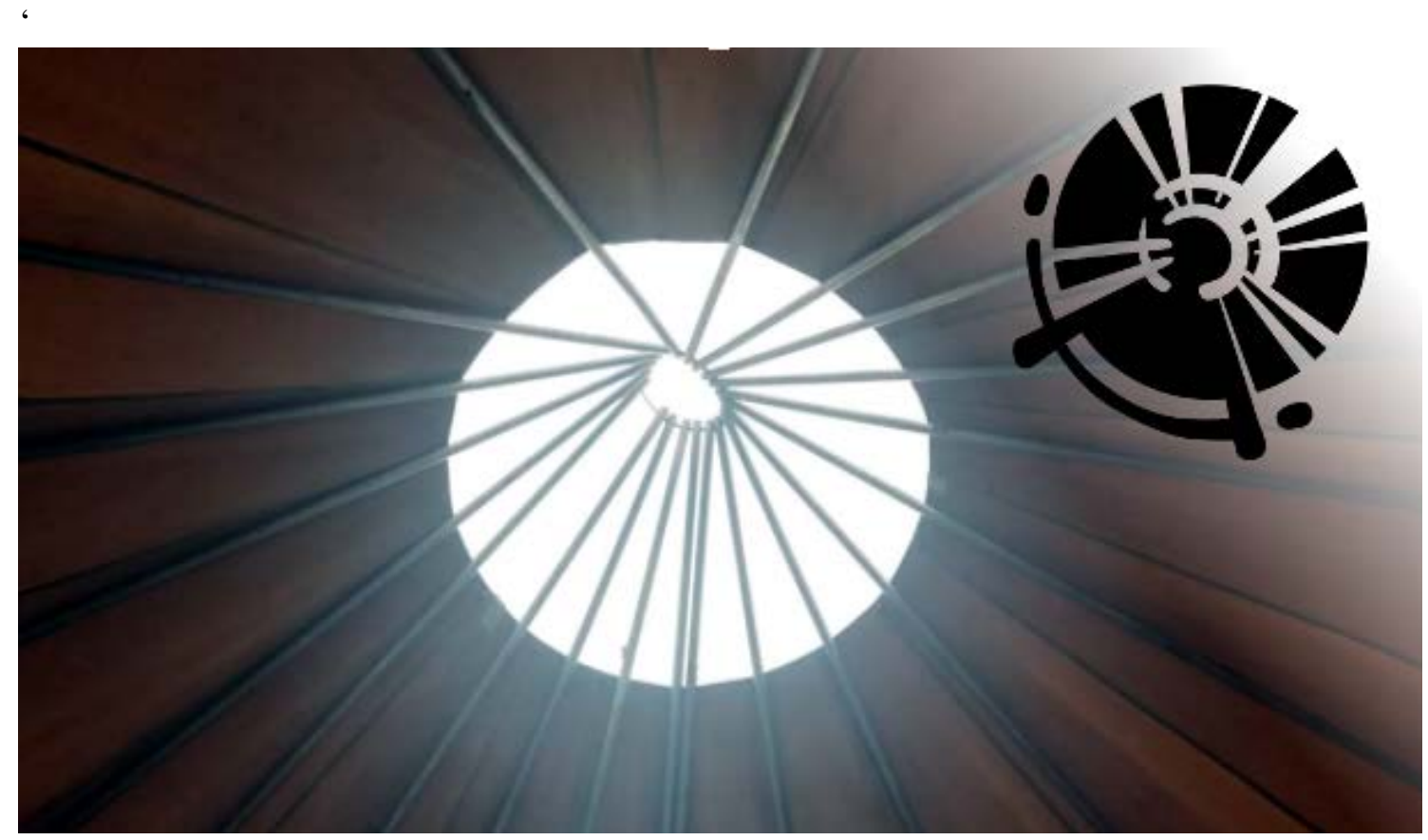

Figure 1. Reahpenráigi-logo next to the smoke hole of lávvu.

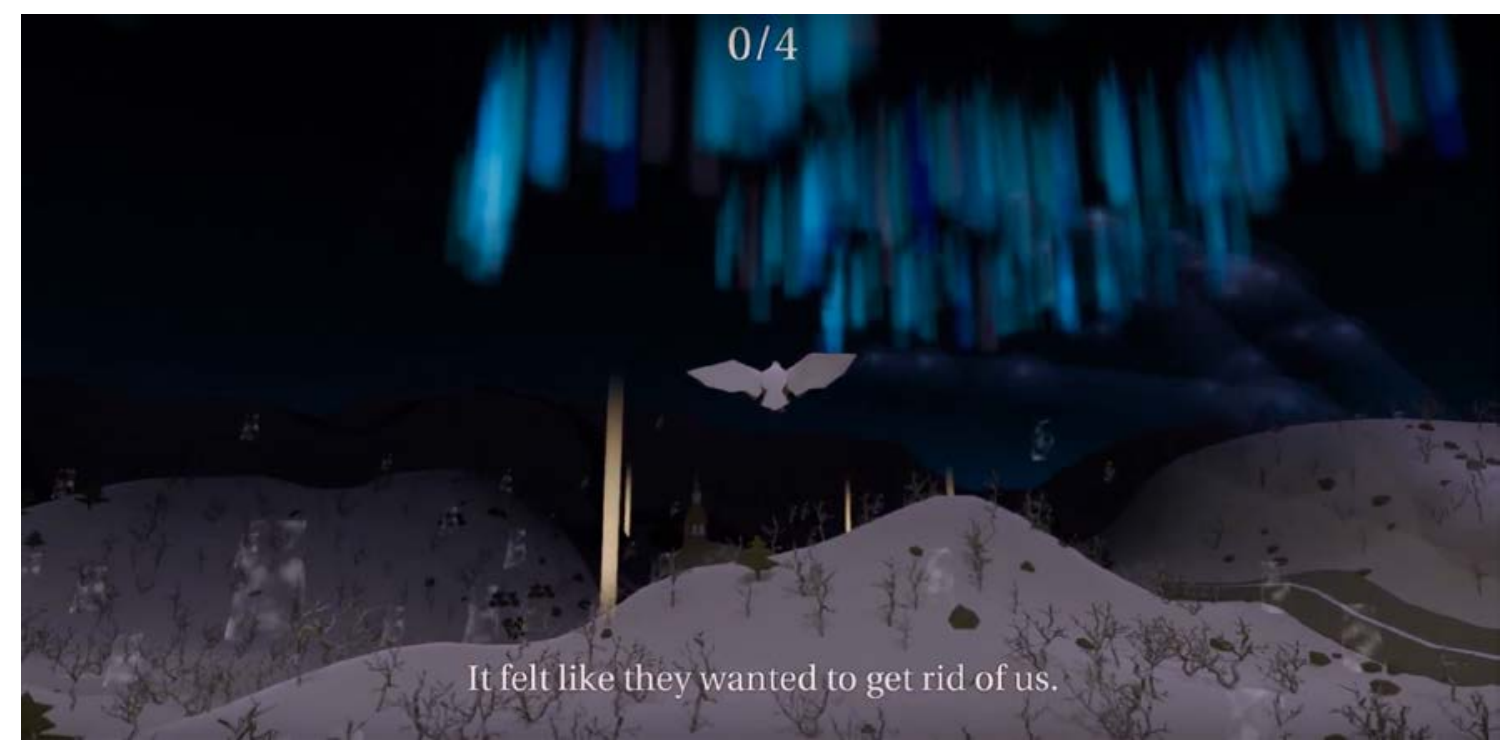

Figure 2. Rievssat flying through eight seasons. 


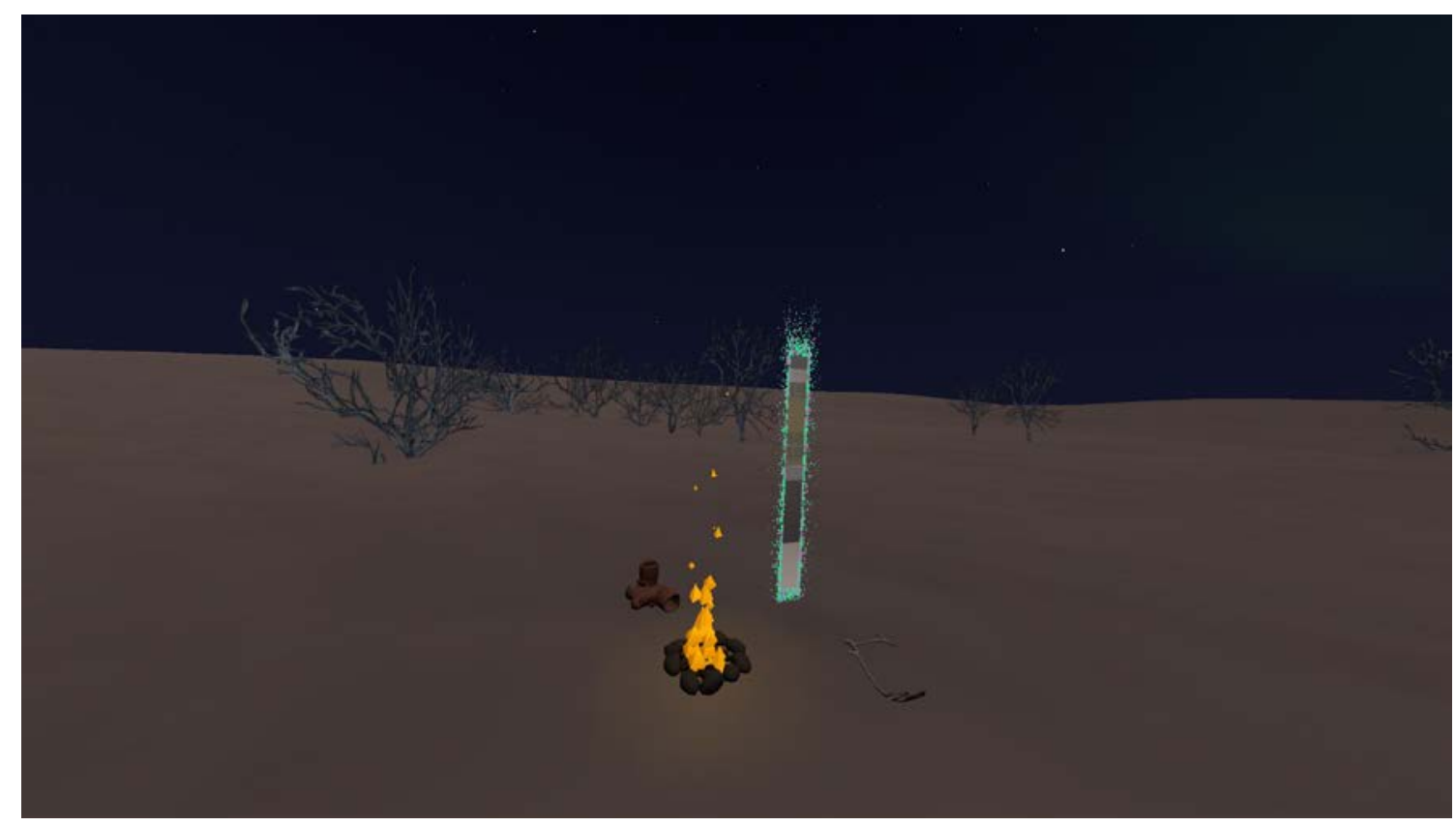

Figure 3. Lost Memories: The Sámiland mountain ambience and the portal

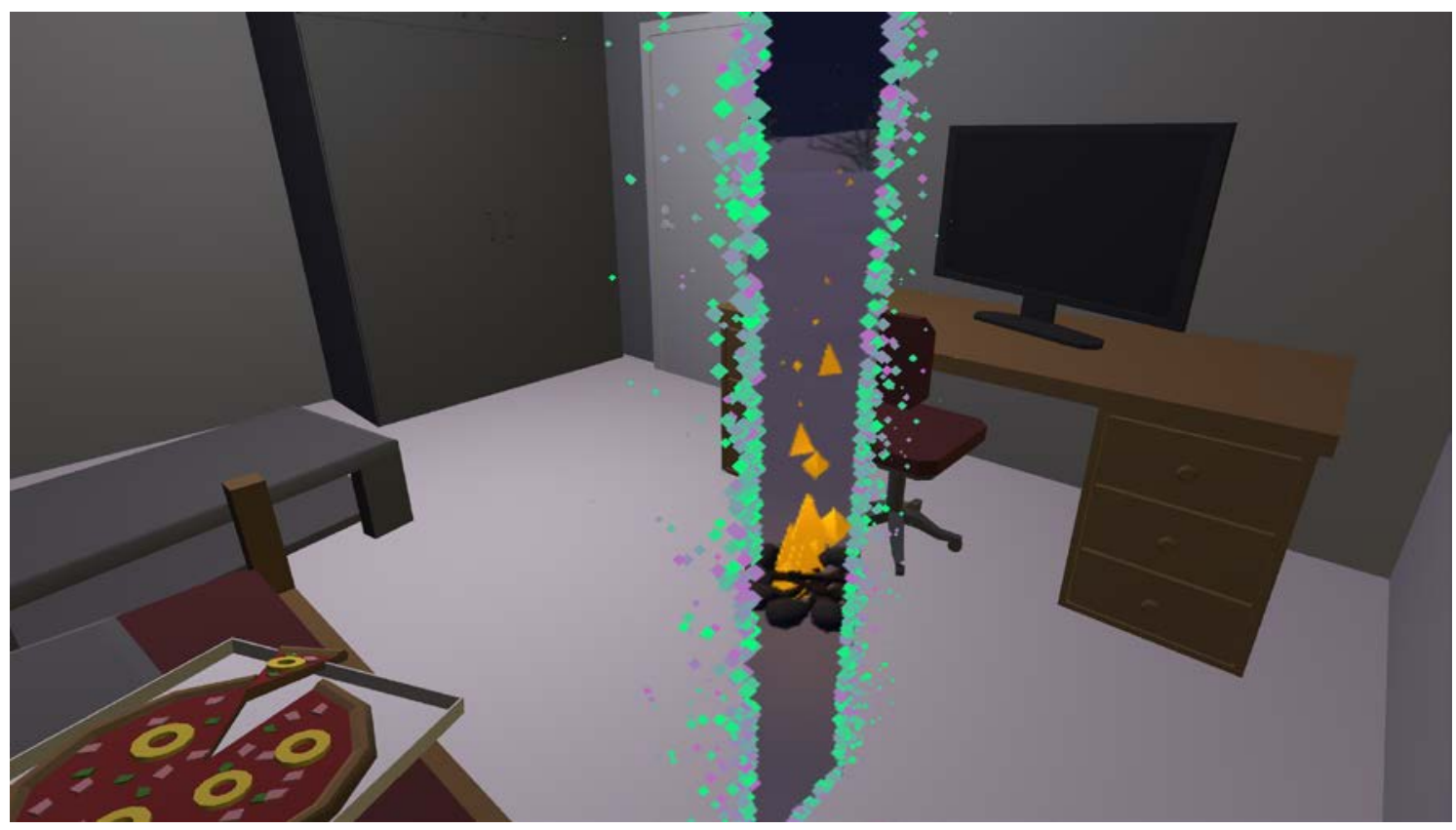

Figure 4. Lost Memories: The city apartment and the portal. 


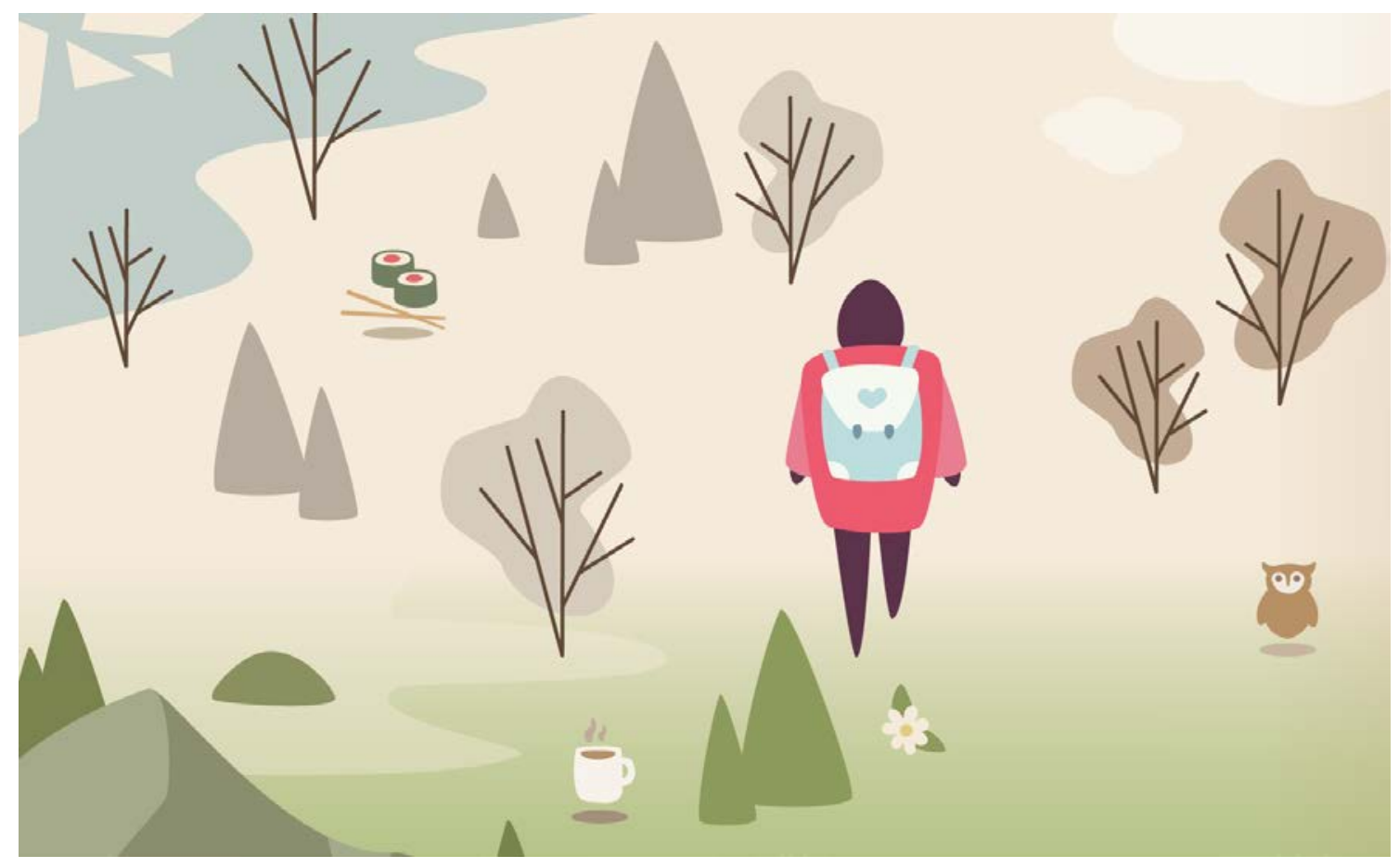

Figure 5. Screen capture from Jođus - On the Move 